\title{
Multisensory cortical processing of object shape and its relation to mental imagery
}

\author{
MINMING ZHANG \\ Emory University School of Medicine, Atlanta, Georgia \\ and Zhejiang University Medical School, Hangzhou, China \\ and \\ VALERIE D. WEISSER, RANDALL STILLA, S. C. PRATHER, and K. SATHIAN \\ Emory University School of Medicine, Atlanta, Georgia
}

\begin{abstract}
Here, we used functional magnetic resonance imaging to investigate the multisensory processing of object shape in the human cerebral cortex and explored the role of mental imagery in such processing. Regions active bilaterally during both visual and haptic shape perception, relative to texture perception in the respective modality, included parts of the superior parietal gyrus, the anterior intraparietal sulcus, and the lateral occipital complex. Of these bimodal regions, the lateral occipital complexes preferred visual over haptic stimuli, whereas the parietal areas preferred haptic over visual stimuli. Whereas most subjects reported little haptic imagery during visual shape perception, experiences of visual imagery during haptic shape perception were common. Across subjects, ratings of the vividness of visual imagery strongly predicted the amount of haptic shape-selective activity in the right, but not in the left, lateral occipital complex. Thus, visual imagery appears to contribute to activation of some, but not all, visual cortical areas during haptic perception.
\end{abstract}

It is now well established that visual cortical activity regularly accompanies normal human tactile perception. This was first shown in a functional neuroimaging study from our laboratory (Sathian, Zangaladze, Hoffman, \& Grafton, 1997). In this study, tactile discrimination of grating orientation recruited an extrastriate region of the parietooccipital cortex (POC) that had previously been reported to be active during visual discrimination of grating orientation (Sergent, Ohta, \& MacDonald, 1992). We later demonstrated that transcranial magnetic stimulation over the POC disrupts the tactile ability to perform grating orientation discrimination (Zangaladze, Epstein, Grafton, \& Sathian, 1999), thus proving that the POC activity contributes to optimal tactile perception. Many groups, including ours, subsequently have found that various visual cortical areas are engaged during tactile perception in a task-specific manner, so that areas of the visual cortex are active during particular types of processing, not only for visual, but also for tactile stimuli (Sathian, Prather, \& Zhang, 2004). Thus, perception of both tactile and visual motion recruits the human MT complex (Blake, Sobel, \& James, 2004; Hagen et al., 2002), and mental rotation of

This work was supported by Grant RO1 EY 12440 to K.S. from the National Eye Institute at the NIH. We thank Xiaoping Hu for his help, Rainer Goebel and Norihiro Sadato for their suggestions, and our subjects for their willing participation. Correspondence concerning this article should be addressed to K. Sathian, Department of Neurology, Emory University School of Medicine, WMRB 6000, 1639 Pierce Drive, Atlanta, GA 30322 (e-mail: ksathia@emory.edu). both tactile (Prather, Votaw, \& Sathian, 2004) and visual (Alivisatos \& Petrides, 1997; Cohen et al., 1996) forms activates a common focus in the intraparietal sulcus (IPS). Haptic object identification, which has been studied by a number of workers (Amedi, Jacobson, Hendler, Malach, \& Zohary, 2002; Amedi, Malach, Hendler, Peled, \& Zohary, 2001; James et al., 2002; Stoeckel et al., 2003), elicits activity in a temporo-occipital region in the ventral visual pathway known as the lateral occipital complex (LOC). LOC activation also occurs during tactile perception of twodimensional (2-D) forms, as shown by recent studies from our laboratory (Prather et al., 2004; Stoesz et al., 2003).

Although there is agreement that tactile perception recruits visual cortical regions, the reasons for such recruitment remain unclear. We have suggested that visual imagery could be responsible, since macrospatial tasks, which show a greater tendency to trigger visual imagery than do microspatial tasks, are also accompanied by more visual cortical involvement (Sathian \& Zangaladze, 2001; Sathian et al., 1997; Stoesz et al., 2003; Zangaladze et al., 1999). However, other groups do not agree with this view, favoring instead the idea that both visual and haptic processing engage a common multisensory representation (Amedi et al., 2002; Amedi et al., 2001; James et al., 2002). The present study used functional magnetic resonance imaging (fMRI) to investigate (1) which regions of the sensory cortex are shape selective during both visual and haptic perception, (2) whether responses in these multisensory regions are stronger for visual or haptic presentations, and (3) the relationship of activity in multisensory regions to mental imagery. 


\section{METHOD}

\section{Subjects}

Eight subjects ( 4 females and 4 males) took part in this study, after giving informed consent. Their ages ranged from 19 to 25 years (mean, 21.6 years). Seven were right-handed, and 1 was left-handed, as assessed by the high-validity subset of the Edinburgh handedness inventory (Raczkowski, Kalat, \& Nebes, 1974). All the subjects were neurologically normal and had vision that was normal or corrected to normal with contact lenses. Subjects with callused fingerpads or a history of injury to the hands or their innervation were excluded, as were those with a history of dyslexia, which is associated with tactile impairments (Grant, Zangaladze, Thiagarajah, \& Sathian, 1999; Sathian et al., 2003). All the procedures were approved by the Institutional Review Board of Emory University.

\section{Stimuli and Tasks}

There were four experimental conditions, two haptic and two visual, with a shape and texture condition in each modality. During the haptic conditions, the subjects actively explored various objects or surfaces with the thumb and first two fingers of the right hand. During the visual conditions, the subjects viewed photographs of various objects or surfaces displayed centrally on a black screen. In the shape conditions, the subjects were instructed to covertly think of words that were descriptive of the geometrical shape of each object presented. In the texture conditions, they were instructed to covertly think of words that described the texture of each surface encountered. The subjects were given examples of each kind of stimulus prior to scanning. These examples were not repeated during subsequent scanning.

In the haptic shape (HS) condition, the stimuli were objects cut out of a stiff foam material. Object shape varied in two dimensions, and object size was designed to allow easy exploration of contour. In the haptic texture (HT) condition, different materials were affixed to both sides of a square piece of cardboard. The shape stimuli were all of the same texture, and the texture stimuli were all of the same shape. The subjects' eyes were closed during haptic exploration, and subjects were never allowed to see the haptic stimuli. The images used for visual presentations were scanned into a computer, grayscaled, and resized to $5^{\circ}$ square, using Adobe Photoshop. The visual shape (VS) condition used photographs of objects or parts of objects, obtained from Microsoft Clip Art or published collections (Blossfeldt, 1997a,1997b; Feinstein, 2001). The subjects could choose to describe the entire visible shape or the shape of a particular component. For the visual texture (VT) condition, commonly available materials or photographs of common textures (Brodatz, 1966) were used to generate the stimuli.

The stimuli, which are listed in Table 1, were chosen on the basis of pilot studies in other subjects. The criteria were that a given stimulus evoked either geometric or textural descriptions, but not both, and that similar descriptors were used by the subjects for both visual and haptic presentations. Our assumption was that asking the subjects to focus on generating descriptions of either shape or texture would elicit processing of the relevant attributes, while keeping linguistic demands constant.

\section{Magnetic Resonance (MR) Scanning}

MR scans were carried out on a 3 Tesla Siemens Trio whole-body scanner, using a standard head coil. Blood oxygenation leveldependent (BOLD) contrast (T2* weighted) functional images were acquired using a single-shot gradient-recalled echoplanar imaging sequence. Thirty horizontal slices of 4-mm thickness were acquired with the following parameters: repetition time (TR), 3,000 msec; echo time (TE), $31 \mathrm{msec}$; matrix size, $64 \times 64 \times 30$; flip angle, $90^{\circ}$; in-plane resolution, $3.4 \times 3.4 \mathrm{~mm}$. High-resolution anatomic images were also acquired, using a 3-D magnetization-prepared rapid gradient-echo sequence (Mugler \& Brookman, 1990) comprising 176 sagittal slices of 1-mm thickness (inversion time [TI], $900 \mathrm{msec}$; TR, 2,600 msec; TE, $3.9 \mathrm{msec}$; flip angle, $8^{\circ}$; matrix size, $176 \times 208 \times$ 256; in-plane resolution, $1 \times 1 \mathrm{~mm}$ ).

The subject lay supine in the scanner with the right arm outstretched. The fourth and fifth fingers of the right hand were flexed and immobilized with adhesive tape secured to the palm. Foam padding under the body and beside the right arm was used to minimize movement and transfer of vibration from the gradient coil, while ensuring the subject's comfort. A mirror positioned above the subject's eyes provided unobstructed visualization of images projected on a screen at the rear magnet aperture. Head restraint straps and foam pads were utilized to minimize head movement. The subjects used ear plugs to muffle scanner noise; additional noise attenuation was provided by headphones that also served to convey verbal instructions. The subjects' eyes remained open throughout the entire functional sequence. The subjects were instructed to fixate on a fixation cross in the center of a black screen during the rest baseline and haptic conditions and to keep the right hand still during the visual conditions. During each haptic trial, an experimenter manually placed the stimulus in the subject's right hand, removing it at the end of the trial. No overt response was required during fMRI scanning. We assumed that activity related to hand movements (for the two haptic conditions) and eye movements (for the two visual conditions) would be similar.

A block design paradigm was employed, comprising alternating blocks with and without stimulation. Block duration was $21 \mathrm{sec}$. Immediately preceding each stimulation block, a screen was presented

Table 1

Stimuli Used During fMRI Scanning and Typical Descriptions Obtained

\begin{tabular}{|c|c|c|}
\hline Condition & Stimuli & Typical Descriptions \\
\hline Haptic shape & $\begin{array}{l}\text { circle } \\
\text { semicircle } \\
\text { heart } \\
\text { star } \\
\text { oval } \\
\text { rectangle } \\
\text { crescent } \\
\text { square } \\
\text { triangle }\end{array}$ & $\begin{array}{l}\text { circular, round } \\
\text { semicircle, half-circle } \\
\text { heart-shaped, triangular } \\
\text { star } \\
\text { oval, circular } \\
\text { rectangular } \\
\text { crescent, moon-shaped } \\
\text { square } \\
\text { triangular }\end{array}$ \\
\hline Haptic texture & $\begin{array}{l}\text { leather } \\
\text { faux fur } \\
\text { carpet backing } \\
\text { carpet } \\
\text { velvet } \\
\text { fleece } \\
\text { burlap } \\
\text { sandpaper } \\
\text { suede microfiber }\end{array}$ & $\begin{array}{l}\text { soft, smooth } \\
\text { furry, fluffy } \\
\text { rough, bumpy } \\
\text { rough } \\
\text { soft, smooth } \\
\text { soft, fluffy } \\
\text { rough, coarse } \\
\text { rough, scratchy } \\
\text { smooth, soft }\end{array}$ \\
\hline Visual shape & $\begin{array}{l}\text { part of guard rail } \\
\text { part of fire hydrant } \\
\text { garlic } \\
\text { grapes } \\
\text { part of hot air balloon } \\
\text { fusilli pasta } \\
\text { peas in a pod } \\
\text { Spanish roof tiles } \\
\text { part of a waffle }\end{array}$ & $\begin{array}{l}\text { cylindrical, circular } \\
\text { pentagonal, round } \\
\text { round, bulbous } \\
\text { oval, egg-shaped } \\
\text { circular, round } \\
\text { spiral, curly-qs } \\
\text { leaf-shaped, round } \\
\text { cylindrical } \\
\text { rectangular, square }\end{array}$ \\
\hline Visual texture & $\begin{array}{l}\text { leather } \\
\text { hand-made paper } \\
\text { tree bark } \\
\text { animal fur } \\
\text { marble } \\
\text { wood grain } \\
\text { ceiling tile } \\
\text { reptile skin } \\
\text { denim }\end{array}$ & $\begin{array}{l}\text { smooth } \\
\text { grainy, bumpy } \\
\text { rough, woody } \\
\text { furry, hairy } \\
\text { jagged, smooth } \\
\text { smooth, wavy } \\
\text { rough, spongy } \\
\text { scaly, bumpy } \\
\text { rough }\end{array}$ \\
\hline
\end{tabular}


for $1 \mathrm{sec}$ to cue the subject as to which condition followed. The words used to identify each condition were tactile texture, tactile shape, visual texture, visual shape, and, for the rest condition, fixate. Each stimulation block contained three stimulus presentations of $6 \mathrm{sec}$ apiece, with a 1 -sec interstimulus interval. The timing of haptic stimulus presentation was guided by cues displayed to the experimenter on a screen. There were 12 stimulation blocks ( 3 per condition) and 13 rest blocks. This resulted in a total of nine trials per condition. A new stimulus was used in each trial. The stimulation blocks were interleaved in a predetermined pseudorandom sequence, using Presentation software (Neurobiobehavioral Systems, Albany, CA) hat also controlled visual stimulus timing and the display of cues to the subject and the experimenter.

\section{Subjective Reports}

Following MR scanning, the Vividness of Visual Imagery Questionnaire (VVIQ) (Marks, 1973) was orally administered to the subjects with their eyes closed. This questionnaire uses a scale of $1-5$ ( 1 being the most vivid) to rate the vividness with which commonplace items can be visually imaged. It thus provides a general index of image vividness and has been used previously as a correlational probe for mediation of haptic processes via visual imagery (e.g., Lederman, Klatzky, Chataway, \& Summers, 1990). The subjects were familiarized with the rating scale before administration of the questionnaire. In addition, the objects and surfaces used during scanning were presented again, and the subjects were asked to report the words they thought of during scanning. At this time, using the VVIQ rating scale, each subject was also asked to provide one score for the vividness of visual imagery experienced overall during HS perception (VI_HS) and another score for the vividness of haptic imagery experienced overall during VS perception (HI_VS). These ratings were intended to index cross-modal mental imagery during shape perception and were deliberately administered after the scanning session so as to avoid biasing the subjects toward the use of such imagery during fMRI scanning.

\section{Image Processing and Analysis}

Image processing and analysis was performed using BrainVoyager 2000 Version 4.91 (Brain Innovation, Maastrict, The Netherlands). Each subject's BOLD images were realigned to the middle image of the series, using a rigid-body transformation procedure. Functional 2-D images were preprocessed with trilinear interpolation for motion correction, sinc-interpolation for slice scan time correction, and high-pass temporal filtering at $1 \mathrm{~Hz}$ to remove slow time drifts and then were coregistered with the anatomic images and transformed into Talairach space (Talairach \& Tournoux, 1988). For group analysis, the transformed data were spatially smoothed with an isotropic Gaussian kernel (full width half maximum $=8 \mathrm{~mm}$ ) and were $z$-normalized. Statistical analysis of group data used fixedeffects, general linear models. Activations were localized with respect to 3-D cortical anatomy with the help of an MRI atlas (Duvernoy, 1999).

Multiple analyses were performed. First, we identified regions that were bimodally shape selective, using the conjunction of contrasts $(\mathrm{HS}-\mathrm{HT})+(\mathrm{VS}-\mathrm{VT})$. In this conjunction analysis, activations were Bonferroni corrected for multiple comparisons $(p<.01)$ within the entire image space. Second, at the peak voxels of the regions of interest (ROIs) thus identified, we compared activity for VS and HS on a direct contrast between these two conditions. Since this comparison was restricted to ROIs taken from the first analysis, a statistical threshold of $p<.05$ (uncorrected) was used. Both these analyses were performed on the grouped data. Finally, we investigated the relationship across subjects between the activation strengths in selected ROIs and imagery ratings, by performing correlations and regressions. This level of analysis employed data from individual subjects in a random-effects design, the individual fMRI data being used without spatial smoothing or $z$-normalizing.

\section{RESULTS}

\section{Group Analyses}

Six regions (Figure 1, Table 2) were bimodally shape selective on the conjunction analysis of (HS - HT) + (VS VT). These regions were located bilaterally in the superior parietal gyrus (SPG), the anterior IPS (aIPS), and the LOC. Figure 2 shows time course data from the activation maxima of these ROIs, demonstrating clearly that the evoked BOLD signal was higher in each shape condition than in the texture condition of the corresponding modality. Furthermore, it is apparent that there was varying modality preference in different regions. Statistical analysis of such modality preferences at the maxima of these ROIs, using the VS - HS contrast (Table 2), revealed that three of the four more dorsal ROIs (the left SPG and the paired aIPS foci) significantly preferred haptic over visual presentation. The right SPG also showed a preference in the same direction, but this was not statistically significant. In both ventral regions (the paired LOC foci), there was a significant preference for visual over haptic stimuli.
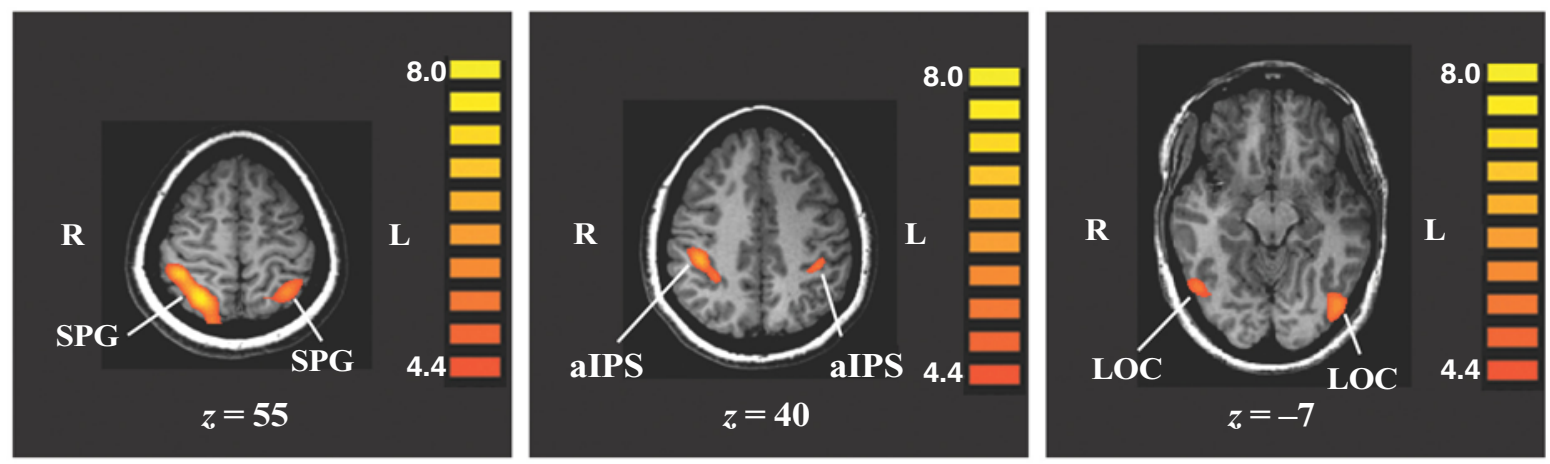

Figure 1. Bimodal shape-selective activations (conjunction of HS - HT and VS - VT), displayed on horizontal MR slices taken from one subject. Display threshold, $t>4.4$; Talairach $z$ value is below and $t$ scale to the right of each image. SPG: superior parietal gyrus; aIPS, anterior intraparietal sulcus; LOC, lateral occipital complex. 
Table 2

Regions Active During Both Visual and Haptic Shape Perception

\begin{tabular}{|c|c|c|c|c|c|}
\hline Site & $x$ & $y$ & $z$ & $\begin{array}{c}t_{\max } \\
(\mathrm{VS}-\mathrm{VT})+(\mathrm{HS}-\mathrm{HT})\end{array}$ & $\begin{array}{c}t \\
(\mathrm{~V}>\mathrm{H}) \\
\end{array}$ \\
\hline L SPG & -29 & -53 & 55 & 6.0 & $-7.2 *$ \\
\hline R SPG & 25 & -58 & 57 & 8.2 & -0.5 \\
\hline L aIPS & -35 & -36 & 40 & 5.5 & $-15.4^{*}$ \\
\hline $\mathrm{R}$ aIPS & 37 & -40 & 50 & 7.9 & $-12.3 *$ \\
\hline L LOC & -42 & -71 & -6 & 6.2 & $8.1^{*}$ \\
\hline R LOC & 50 & -59 & -7 & 5.7 & $2.9^{*}$ \\
\hline
\end{tabular}

Note-See the text for details and for abbreviations; $x, y, z$, Talairach coordinates of activation maxima in grouped data for the conjunction of visual (VS - VT) and haptic (HS - HT) shape effects; $t_{\max }$ values are listed for these sites $(p<.01$, Bonferronicorrected for multiple comparisons within the entire brain). Rightmost column lists $t$ values (at maxima of the conjunction ROIs) for visual preference $(\mathrm{V}>\mathrm{H}$; negative values represent $\mathrm{H}>\mathrm{V})$. *Significant at $p<.05$, uncorrected.

\section{Subjective Reports}

Table 1 lists the typical descriptions used by the subjects for the various shape and texture stimuli. As in the pilot studies, the descriptors were generally similar across modalities, while differing for tasks (shape vs. texture). Although both visual imagery ratings (VVIQ and VI_HS) showed a good deal of intersubject variability, the haptic imagery ratings (HI_VS) were much less variable and reflected little tendency to use haptic imagery during VS (Table 3). Hence, the haptic imagery ratings will not be considered further.

\section{Individual Subject Analyses}

In order to address the potential relationship between visual cortical activation and visual imagery during haptic perception, we focused on the two regions with a significant preference for visual over haptic stimuli (i.e., both LOC ROIs). These ROIs were defined in individual subjects, using the VS - VT contrast, which is an accepted method of defining the LOC (Malach et al., 1995). A consistent statistical threshold of $t>2.8$ ( $p<.006$, uncorrected) was used in all the subjects. The ROIs were constrained to be a maximum of $729 \mathrm{~mm}^{3}$ in volume (i.e., a cube of 9 -mm side). As Table 3 shows, the ROIs were all smaller than this arbitrary maximum. In each subject, over the ROIs thus defined, the beta weights for the VS - VT and HS - HT contrasts were determined (Table 3 ). These beta weights were taken to index the strength of shapeselective activity in the LOC. As Table 3 shows, the beta weights and the visual imagery ratings exhibited substantial intersubject variability. Hence, these beta weights and the visual imagery ratings were used to perform the correlations listed in Table 4.

A few points emerge from these correlations. First, the two ratings of visual imagery, VVIQ and VI_HS, were essentially uncorrelated. Second, the beta weights in the left and the right LOC were significantly correlated for visual, but not haptic shape-selective activity. Third, the beta weights in each LOC were uncorrelated between visual and haptic shape-selective activity. Fourth, the beta weight for visual shape-selective activity in the right, but not the left, LOC correlated significantly with VVIQ, whereas neither of these beta weights correlated with VI_HS. Finally, the beta weights for haptic shape-selective activity were not significantly correlated with either imagery rating, although the correlations for the right LOC were fairly high and approached significance. Note that, owing to the nature of the rating scales used ( 1 being the most vivid and 5 the least vivid), a negative correlation with an imagery rating score indicates that more vivid imagery is associated with stronger activations.

Given that the VVIQ and the VI_HS scores were uncorrelated, we next asked whether the combination of these two scores could predict the strength of LOC activity. This possibility seemed especially attractive in the case of the right LOC for the haptic shape-selective beta weights, where each imagery score yielded a relatively high correlation, albeit short of significance. To test this idea, a multiple regression analysis was performed for each LOC, using the haptic shape-selective beta weight as the dependent variable and the two visual imagery scores as independent variables. The results are shown in Table 5 . (The single regressions on VVIQ and VI_HS do not add much information to the correlations already considered and are included in Table 5 merely for emphasis.) The main point is that the multiple regression has no predictive value for the left LOC, whereas for the right LOC, it is not only highly significant but also accounts for $90 \%$ of the variance in the haptic shape-selective beta weight.

Although one of our subjects (No. 8) was left-handed, we do not believe that this materially affects our results. The imagery scores and beta weights did not stand out in any way from the other subjects'. Furthermore, we repeated the regression analysis of LOC beta weights on imagery ratings with this subject's data excluded and found that the results were essentially similar (data not shown).

\section{DISCUSSION}

The main conclusions of the present study are that (1) a set of bilateral regions in the SPG, aIPS, and LOC is shape selective during both visual and haptic perception, (2) these bimodal regions can be segregated into a dorsal, parietal group (bilateral SPG and aIPS) showing a relative prefer- 

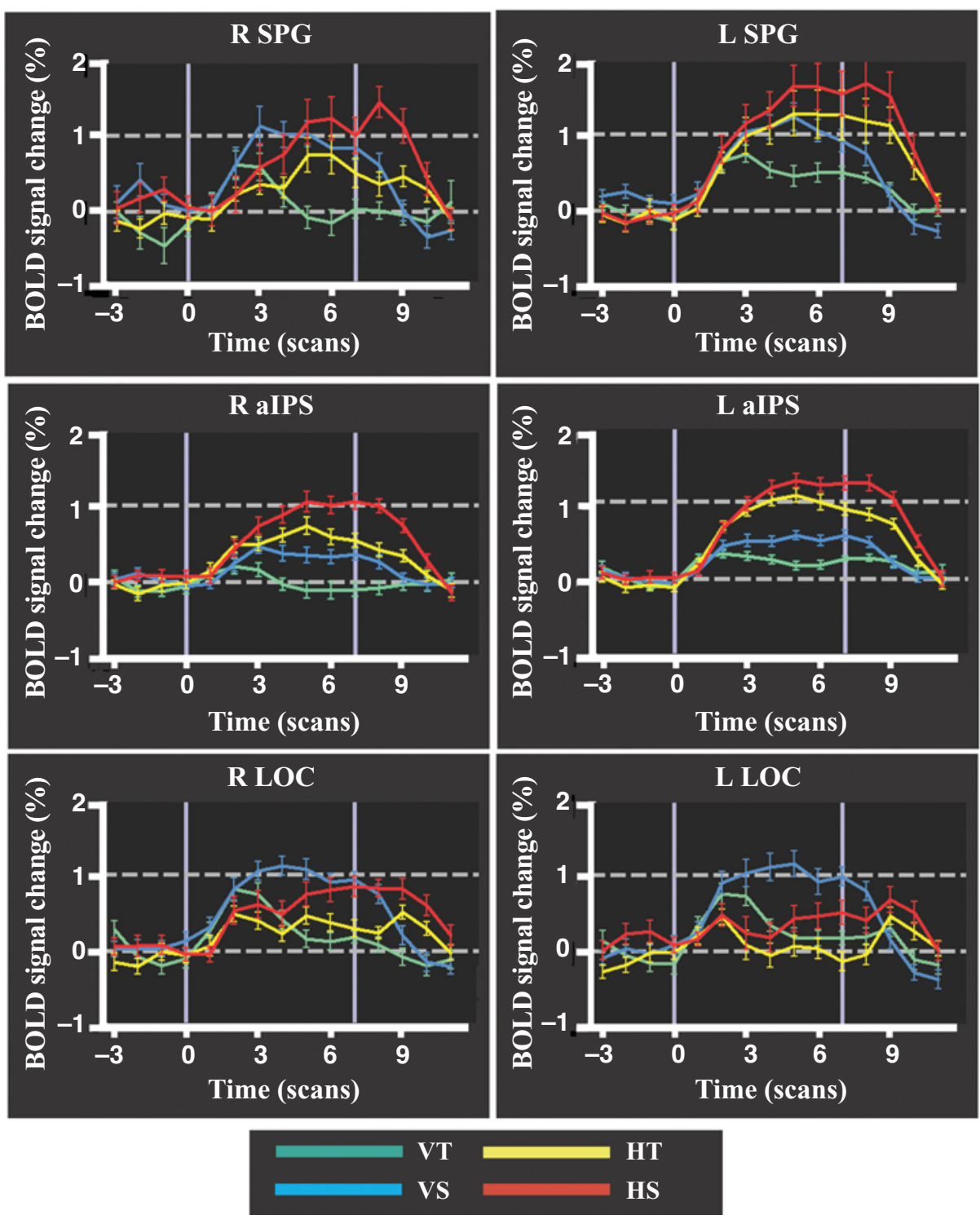

Figure 2. Time course of BOLD signal change (mean $\pm S E M)$ at maxima of activations shown in Figure 1; each scan lasted 3 sec. See text for details. R, right; L, left; SPG, superior parietal gyrus; aIPS, anterior intraparietal sulcus; LOC, lateral occipital complex.

ence for haptic stimuli and a ventral, occipito-temporal group (bilateral LOC) showing a relative preference for visual stimuli, and (3) across subjects, the strength of activation by HS perception in the right, but not the left, LOC is predicted by ratings of the vividness of visual imagery.

A few words on experimental design are in order. Our design relied on contrasting shape and texture perception in each modality. The contrast between shape and texture conditions is a standard method of investigating shapeselective processing (Amedi et al., 2002; Amedi et al., 2001; Malach et al., 1995). Although the subjects engaged only in covert description of shapes and textures, their subsequent recall of the descriptors used during scanning affords some measure of confidence that they did, indeed, focus on the relevant stimulus attributes in each condition. Moreover, there was statistically significant bimodal shape selectivity in a number of regions, at a conservative statistical threshold, despite the fact that the shape and texture stimuli were not strictly balanced for their detailed stimulus characteristics. Since it is difficult to achieve such balance for haptic stimuli, we also chose not to attempt it for visual stimuli.

\section{Cortical Areas Common to VS and HS perception}

The LOC was originally described as a visual-objectselective region in the occipito-temporal cortex (Malach et al., 1995) and is thought to be homologous to macaque 
Table 3

Individual Subject Data, Including Imagery Scores and Details of Lateral Occipital Complex (LOC) Regions of Interest (ROIs;

Volume, Talairach Coordinates of Activation Maxima in Each Subject, and Beta Weights for Visual (VS - VT) and Haptic (HS - HT) Shape Effects)

\begin{tabular}{|c|c|c|c|c|c|c|c|c|}
\hline & \multicolumn{8}{|c|}{ Subject } \\
\hline & 1 & 2 & 3 & 4 & 5 & 6 & 7 & 8 \\
\hline VVIQ & 35 & 27 & 25 & 41 & 44 & 26 & 30 & 27 \\
\hline VI_HS & 5 & 5 & 1 & 2 & 2 & 1 & 2 & 5 \\
\hline HI_VS & 5 & 5 & 5 & 4 & 5 & 5 & 5 & 1 \\
\hline \multicolumn{9}{|c|}{ Left LOC ROI } \\
\hline Volume $\left(\mathrm{mm}^{3}\right)$ & 714 & 683 & 714 & 622 & 505 & 64 & 361 & 625 \\
\hline$x$ & -38 & -40 & -45 & -54 & -52 & -46 & -43 & -37 \\
\hline$y$ & -63 & -64 & -73 & -51 & -49 & -69 & -75 & -70 \\
\hline$z$ & -1 & -2 & -5 & 2 & -2 & -13 & -8 & -6 \\
\hline $\mathrm{VS}-\mathrm{VT}$ & 15.5 & 14.6 & 13.8 & 4.9 & 4.4 & 6.5 & 7.2 & 9.4 \\
\hline $\mathrm{HS}-\mathrm{HT}$ & 1.4 & -4.1 & 9.1 & 0.7 & 3.3 & -2.2 & 5.6 & 4.2 \\
\hline \multicolumn{9}{|c|}{ Right LOC ROI } \\
\hline Volume $\left(\mathrm{mm}^{3}\right)$ & 520 & 602 & 698 & 709 & 387 & 296 & 261 & 719 \\
\hline$x$ & 50 & 51 & 48 & 53 & 47 & 47 & 43 & 45 \\
\hline$y$ & -65 & -58 & -58 & -55 & -56 & -60 & -75 & -65 \\
\hline$z$ & -3 & 0 & -7 & -5 & 1 & -7 & -5 & -3 \\
\hline $\mathrm{VS}-\mathrm{VT}$ & 11.2 & 14.4 & 12.6 & 7.4 & 0.3 & 11.2 & 7.2 & 10.7 \\
\hline $\mathrm{HS}-\mathrm{HT}$ & -2.3 & 0.4 & 9.8 & 1 & 0.2 & 12.2 & 4.2 & 4.2 \\
\hline
\end{tabular}

Note- See the text for further details and for abbreviations.

inferotemporal cortex (Grill-Spector et al., 1998). Not surprisingly, we found a relative preference for visual over haptic stimuli in the LOC in both hemispheres. LOC activity in the present study was also selective for object geometry, relative to texture, whether stimuli were presented visually or haptically, as was described previously (Amedi et al., 2002; Amedi et al., 2001). Prior studies showed that parts of the LOC in both hemispheres are active during both visual and haptic object exploration
(Amedi et al., 2002; Amedi et al., 2001; James et al., 2002). The LOC has been found, in other studies from our laboratory (Prather et al., 2004; Stoesz et al., 2003), to be recruited by tactile perception of 2-D forms presented to the passive right hand. One of these studies showed LOC activity only on the right (Prather et al., 2004), whereas the other showed bilateral activity (Stoesz et al., 2003). In the present study, the activations were correlated in strength between the two sides for VS, which was to be expected

Table 4

Correlations Across Subjects Between Beta Weights for Visual (VS VT) and Haptic (HS - HT) Shape Effects and Visual Imagery Scores

\begin{tabular}{crrr}
\hline Variable 1 & Variable 2 & $r$ & $p$ \\
\hline & Correlations Between Visual Imagery Scores & \\
VVIQ & VI_HS & -.08 & .86
\end{tabular}

Correlations Between Activity in Left and Right LOC

$\begin{array}{llll}\text { L LOC VS - VT } & \text { R LOC VS - VT } & .76 & .03 * \\ \text { L LOC HS - HT } & \text { R LOC HS - HT } & .22 & .6\end{array}$

Correlations Between Visual and Haptic Shape-Selective Activity
L LOC VS - VT
L LOC HS - HT
$-.01$
.99
R LOC VS - VT
R LOC HS - HT
.29
.49

Correlations Between Visual Shape-Selective Activity and Visual Imagery Scores

$\begin{array}{llrl}\text { L LOC VS - VT } & \text { VVIQ } & -.51 & .20 \\ \text { L LOC VS - VT } & \text { VI_HS } & .55 & .16 \\ \text { R LOC VS - VT } & \text { VVIQ } & -.81 & .01 * \\ \text { R LOC VS - VT } & \text { VI_HS } & .35 & .39\end{array}$

Correlations Between Haptic Shape-Selective Activity and Visual Imagery Scores

\begin{tabular}{llll} 
L LOC HS - HT & VVIQ & -.05 & .92 \\
L LOC HS - HT & VI_HS & -.34 & .41 \\
R LOC HS - HT & VVIQ & -.64 & .09 \\
R LOC HS - HT & VI_HS & -.65 & .08 \\
\hline
\end{tabular}

Note-L, left; R, right; LOC, lateral occipital complex. *Significant correlation $(p<.05)$. 
Table 5

Results of Regression Analysis of Beta Weights for Haptic Shape-Selective Activity on Imagery Scores

VVIQ and VI_HS (multiple regression)

\begin{tabular}{cccc} 
& VVIQ & VI_HS & (multiple regression) \\
\hline & \multicolumn{3}{c}{ Left LOC } \\
$R^{2}$ & .002 & .11 & .11 \\
$p$ & .92 & .41 & .73 \\
& & Right LOC & \\
$R^{2}$ & .41 & .42 & .9 \\
$p$ & .09 & .08 & $.003^{*}$ \\
\hline
\end{tabular}

Note-LOC, lateral occipital complex. * *Significant effect $(p<.05)$.

given that our visual stimuli spanned the midline. The LOC is engaged bilaterally by a stimulus in either visual field (Grill-Spector et al., 1998); it would be interesting to know whether activity levels between the two sides are correlated for unilateral stimuli. For HS with stimuli presented to the right hand, left and right LOC beta weights were uncorrelated in the present study, suggesting that different mechanisms might be involved in the two hemispheres. This is supported by the correlational analysis, as will be discussed below. Furthermore, the lack of correlation on either side between VS and HS activation strengths implies that interindividual variations in activity levels may not depend on the same factors in both sensory modalities.

The cortex around the IPS was reported previously to be active during both visual and haptic object perception (Amedi et al., 2001), but the exact parts of the IPS involved were not specified. The present study localizes common visual and haptic processing of shapes to foci in the aIPS bilaterally. The left aIPS site was termed IPA by Bodegård, Geyer, Grefkes, Zilles, \& Roland (2001), who characterized this focus as unimodal, processing somatosensory, but not visual, information. However, this characterization was based on comparisons across different studies, whereas the present study, in which stimuli were presented in both modalities, demonstrates that this is actually a multisensory focus. This is not surprising, given its proximity to other, more laterally located multisensory foci that are active during various tasks, including visual or haptic object recognition and visuo-haptic matching of objects (Grefkes, Weiss, Zilles, \& Fink, 2002), attending to contralateral visual or tactile stimuli (Macaluso, Frith, \& Driver, 2002), mentally rotating stimuli in visual (Cohen et al., 1996) or tactile (Prather et al., 2004) space, and motion processing of visual, auditory, or tactile stimuli (Bremmer et al., 2001). The right aIPS focus has not, to our knowledge, previously been reported to be multisensory. The preference, in the present study, of both aIPS sites for haptic over visual stimuli suggests that somatosensory information is likely to be dominant at these foci.

In the present study, the SPG was also recruited bilaterally during HS, as well as VS, perception, with stronger activation for haptic than for visual stimuli (although the difference between modalities was significant only for the left SPG). Other studies have implicated these foci in both the spatial deployment of visual attention (Leonards,
Sunaert, Van Hecke, \& Orban, 2000; Vandenberghe, Gitelman, Parrish, \& Mesulam, 2001) and kinesthesis (Binkofski et al., 1999; Lloyd, Shore, Spence, \& Calvert, 2003), so that there is a precedent for considering these regions to be multisensory. How contributions to shape perception might differ between the various parietal foci and between these foci and the LOCs is presently unclear.

\section{Relation of Multisensory Activity to Visual Imagery}

One question that has vexed the field is whether cortical regions associated primarily with one modality are recruited cross-modally by bottom-up (feedforward) inputs, top-down (feedback) inputs, or both. We have previously suggested, on the basis of observations that macrospatial tasks tend to evoke both more visual imagery and more visual cortical involvement than do microspatial tasks (Sathian \& Zangaladze, 2001; Sathian et al., 1997; Stoesz et al., 2003; Zangaladze et al., 1999), that visual imagery could mediate cross-modal engagement of visual cortical areas during tactile tasks. According to this idea, visual cortical areas are recruited by tactile tasks via top-down mechanisms, perhaps because these areas are best suited to or most frequently used for the analysis of object geometry. This can be viewed as a specific instantiation of a general principle that information is translated into the format appropriate for the most adept modality, as was proposed 3 decades ago (Freides, 1974). Clear activity has, in fact, been found in the left LOC during mental imagery of object shape based on prior visual exposure in sighted subjects and haptic exposure in blind subjects (De Volder et al., 2001). On the other hand, some have argued against visual imagery as the basis for visual cortical engagement (Amedi et al., 2002; Amedi et al., 2001; James et al., 2002), since auditory objects (Amedi et al., 2002) and visual imagery (Amedi et al., 2001) fail to evoke substantial activity in the LOC, as compared with haptic or visual object perception.

The results of the present study do not definitively resolve this controversy but do offer further support for the notion that visual imagery is associated with recruitment of visual processing areas in nonvisual tasks. We found a novel and interesting dissociation between right and left LOC: Left LOC shape-selective activity during haptic perception appeared to be unrelated to visual imagery, since its strength was not predicted by VVIQ ratings, VI_HS scores, or a multiple regression on both. In contrast, in the right LOC, shape-selective activity during haptic perception was predicted very well by a multiple regression on VVIQ and VI_HS scores together. At present, it is uncertain whether these differences between the right and the left LOC should be interpreted as exemplifying hemispheric specialization or merely as characteristics of the LOC in the hemisphere ipsilateral or contralateral to the exploring hand. To distinguish between these alternatives requires repeating our study with the left hand being used for haptic perception. However, since right, but not left, LOC activity was correlated with VVIQ for central visual stimuli, the right LOC may indeed be preferentially involved in 
form imagery in both vision and touch. Further work is necessary to investigate this possibility.

Our findings strongly implicate visual imagery in recruitment of the right LOC. The results cannot be explained by a nonspecific tendency for right LOC activity to scale up and down between individuals regardless of task, for the following reasons. (1) Right LOC shape-selective activity during visual perception correlated significantly with VVIQ alone, whereas that during haptic perception did not. (2) Visually and haptically evoked activities were not correlated with each other. It could be argued that visual imagery was simply an epiphenomenon, a by-product that had nothing to do with perceptual processing of object shape, and we cannot absolutely exclude this possibility. Nevertheless, our results fit with the concept that visual imagery underlies visual cortical recruitment during haptic perception. The converse, however, does not appear to be true, since haptic imagery was hardly used during visual shape perception. This asymmetry is consistent with the dominance of vision over haptics in shape perception (Klatzky, Lederman, \& Reed, 1987; Rock \& Victor, 1964).

If visual imagery is a possible trigger for right LOC engagement during HS perception, what mechanism could recruit the left LOC? One possibility is that verbal factors might be involved, although this seems unlikely given the similar linguistic demands of the shape and texture tasks. Alternatively, left LOC activity might reflect a common multisensory representation of shape that can be accessed via either visual or haptic inputs. If this is the case, however, the lack of correlation between VS- and HS-selective activity implies that inter-individual variability in the strength of visual inputs into the LOC is independent of that for haptic inputs. Multiple lines of evidence point to representations of object geometry that are shared between vision and haptics. First, psychophysical work shows that visuo-haptic priming is as effective as within-modality priming (Easton, Greene, \& Srinivas, 1997; Easton, Srinivas, \& Greene, 1997; Reales \& Ballesteros, 1999). Second, imaging data reveal that prior visual and haptic exploration produces equivalent priming effects on fMRI responses in the LOC to subsequently viewed objects (James et al., 2002). Third, a patient with visual agnosia due to a left occipito-temporal lesion also had tactile agnosia despite intact basic somatosensory function (Feinberg, Rothi, \& Heilman, 1986), and a prosopagnosic patient demonstrated similar abnormalities of face recognition for visual and haptic presentations (Kilgour, de Gelder, \& Lederman, 2004). It is worth noting that multisensory representations might be accessible either via bottom-up or topdown connections. Recent studies of multisensory inputs into early sensory cortical areas that are traditionally considered to be unimodal have suggested that some inputs are probably top down (Falchier, Clavagnier, Barone, \& Kennedy, 2002; Rockland \& Ojima, 2003; Schroeder et al., 2003), whereas others might be bottom up (Schroeder et al., 2003). An important issue for future research to address is the relative role of bottom-up and top-down mechanisms in multisensory processes.

\section{REFERENCES}

Alivisatos, B., \& Petrides, M. (1997). Functional activation of the human brain during mental rotation. Neuropsychologia, 36, 111-118. Amedi, A., Jacobson, G., Hendler, T., Malach, R., \& Zohary, E. (2002). Convergence of visual and tactile shape processing in the human lateral occipital complex. Cerebral Cortex, 12, 1202-1212.

Amedi, A., Malach, R., Hendler, T., Peled, S., \& Zohary, E. (2001). Visuo-haptic object-related activation in the ventral visual pathway. Nature Neuroscience, 4, 324-330.

BinKofSKi, F., Buccino, G., Posse, S., Seitz, R. J., Rizzolatti, G., \& FREUND, H.-J. (1999). A fronto-parietal circuit for object manipulation in man: Evidence from an fMRI-study. European Journal of Neuroscience, 11, 3276-3286.

BLAKE, R., SOBEL, K. V., \& JAMES, T. W. (2004). Neural synergy between kinetic vision and touch. Psychological Science, 15, 397-402.

BLossfeldT, K. (1997a). The alphabet of plants (A. Wilde \& J. Wilde, Eds.). New York: te Neues Publishing.

BlossfeldT, K. (1997b). Photography (A. Wilde \& J. Wilde, Eds.). New York: Distributed Art Publishers.

Bodegård, A., Geyer, S., Grefkes, C., Zilles, K., \& Roland, P. E. (2001). Hierarchical processing of tactile shape in the human brain. Neuron, 31, 317-328.

Bremmer, F., Schlack, A., Shah, N. J., Zafiris, O., Kubischik, M., Hoffmann, K., Zilles, K., \& Fink, G. R. (2001). Polymodal motion processing in posterior parietal and premotor cortex: A human fMRI study strongly implies equivalencies between humans and monkeys. Neuron, 29, 287-296.

BroDATZ, P. (1966). Textures: A photographic album for artists and designers. Mineola, NY: Dover.

Cohen, M. S., Kosslyn, S. M., Breiter, H. C., DiGirolamo, G. J., Thompson, W. L., ANderson, A. K., Bookheimer, S. Y., Rosen, B. R., \& Belliveau, J. W. (1996). Changes in cortical activity during mental rotation: A mapping study using functional MRI. Brain, 119, 89100.

De Volder, A. G., Toyama, H., Kimura, Y., Kiyosawa, M., Nakano, H., Vanlierde, A., Wanet-Defalque, M. C., Mishina, M., Oda, K., IshiWATA, K., \& SENDA, M. (2001). Auditory triggered mental imagery of shape involves visual association areas in early blind humans. NeuroImage, 14, 129-139.

DUVERNOY, H. M. (1999). The human brain: Surface, blood supply and three-dimensional sectional anatomy (2nd ed.). New York: SpringerVerlag.

Easton, R. D., Greene, A. J., \& Srinivas, K. (1997). Transfer between vision and haptics: Memory for 2-D patterns and 3-D objects. Psychonomic Bulletin \& Review, 4, 403-410.

Easton, R. D., Srinivas, K., \& Greene, A. J. (1997). Do vision and haptics share common representations? Implicit and explicit memory within and between modalities. Journal of Experimental Psycholology: Learning, Memory, \& Cognition, 23, 153-163.

Falchier, A., Clavagnier, S., Barone, P., \& Kennedy, H. (2002). Anatomical evidence of multimodal integration in primate striate cortex. Journal of Neuroscience, 22, 5749-5759.

FeinberG, T. E., Rothi, L. J., \& HeIlman, K. M. (1986). Multimodal agnosia after unilateral left hemisphere lesion. Neurology, 36, 864-867.

Feinstein, H. (2001). Foliage. Boston: Bulfinch Press.

FreIDES, D. (1974). Human information processing and sensory modality: Cross-modal functions, information complexity, memory and deficit. Psychological Bulletin, 81, 284-310.

Grant, A. C., Zangaladze, A., Thiagarajah, M. C., \& Sathian, K. (1999). Tactile perception in developmental dyslexia: A psychophysical study using gratings. Neuropsychologia, 37, 1201-1211.

Grefkes, C., Weiss, P. H., Zilles, K., \& FinK, G. R. (2002). Crossmodal processing of object features in human anterior intraparietal cortex: An fMRI study implies equivalencies between humans and monkeys. Neuron, 35, 173-184.

Grill-Spector, K., Kushnir, T., Hendler, T., Edelman, S., ITZCHAK, Y., \& MALACH, R. (1998). A sequence of object-processing stages revealed by fMRI in the human occipital lobe. Human Brain Mapping, 6, 316-328.

Hagen, M. C., Franzen, O., McGlone, F., Essick, G., Dancer, C., \& PARDo, J. V. (2002). Tactile motion activates the human middle 
tempora1/V5 (MT/V5) complex. European Journal of Neuroscience, 16, 957-964.

James, T. W., Humphrey, G. K., Gati, J. S., Servos, P., Menon, R. S., \& Goodale, M. A. (2002). Haptic study of three-dimensional objects activates extrastriate visual areas. Neuropsychologia, 40, 1706-1714.

Kilgour, A. R., De Gelder, B., \& Lederman, S. J. (2004). Haptic face recognition and prosopagnosia. Neuropsychologia, 42, 707-712.

KLATZKY, R. L., Lederman, S. J., \& ReED, C. (1987). There's more to touch than meets the eye: The salience of object attributes for haptics with and without vision. Journal of Experimental Psychology: General, 116, 356-369.

Lederman, S. J., Klatzky, R. L., Chataway, C., \& Summers, C. D. (1990). Visual mediation and the haptic recognition of two-dimensional pictures of common objects. Perception \& Psychophysics, 47, 54-64.

Leonards, U., Sunaert, S., Van Hecke, P., \& Orban, G. A. (2000). Attention mechanisms in visual search: An fMRI study. Journal of Cognitive Neuroscience, 12, 61-75.

Lloyd, D. M., Shore, D. I., SPENCE, C., \& Calvert, G. A. (2003). Multisensory representation of limb position in human premotor cortex. Nature Neuroscience, 6, 17-18.

Macaluso, E., Frith, C. D., \& Driver, J. (2002). Directing attention to locations and to sensory modalities: Multiple levels of selective processing revealed with PET. Cerebral Cortex, 12, 357-368.

Malach, R., Reppas, J. B., Benson, R. R., Kwong, K. K., Jiang, H., Kennedy, W. A., Ledden, P. J., Brady, T. J. Rosen, B. R., \& Tootell, R. B. H. (1995). Object-related activity revealed by functional magnetic resonance imaging in human occipital cortex. Proceedings of the National Academy of the Sciences, 92, 8135-8139.

MARKS, D. F. (1973). Visual imagery differences in the recall of pictures. British Journal of Psychology, 64, 17-24.

Mugler, J. P., \& Brookman, J. R. (1990). Three dimensional magnetization-prepared rapid gradient-echo imaging (3D MPRAGE). Magnetic Resonance Medicine, 15, 152-157.

PrATHER, S. C., VotaW, J. R., \& SATHIAN, K. (2004). Task-specific recruitment of dorsal and ventral visual areas during tactile perception. Neuropsychologia, 42, 1079-1087.

RACZKOWSKI, D., KALAT, J. W., \& NEBES, R. (1974). Reliability and validity of some handedness questionnaire items. Neuropsychologia, $\mathbf{1 2}$, 43-47.

REAles, J. M., \& BALlesteros, S. (1999). Implicit and explicit memory for visual and haptic objects: Cross-modal priming depends on structural descriptions. Journal of Experimental Psychology: Learning, Memory, \& Cognition, 25, 644-663.

RocK, I., \& VICTOR, J. (1964). Vision and touch: An experimentally created conflict between the two senses. Science, 143, 594-596.
Rockland, K. S., \& OJIMA, H. (2003). Multisensory convergence in calcarine visual areas in macaque monkey. International Journal of Psychophysiology, 50, 19-26.

Sathian, K., Cascio, C., Rice, D., Morris, M., Dancer, C., \& MCGLONE, F. (2003). Is tactile temporal processing impaired in developmental dyslexia? Cognitive Neuroscience Society Abstracts, E323. p. 192.

Sathian, K., Prather, S. C., \& Zhang, M. (2004). Visual cortical involvement in normal tactile perception. In G. Calvert, C. Spence, \& B. Stein (Eds.), The handbook of multisensory processes (pp. 703709). Cambridge, MA: MIT Press.

Sathian, K., \& Zangaladze, A. (2001). Feeling with the mind's eye: The role of visual imagery in tactile perception. Optometry \& Vision Science, 78, 276-281.

Sathian, K., Zangaladze, A., Hoffman, J. M., \& Grafton, S. T. (1997). Feeling with the mind's eye. NeuroReport, 8, 3877-3881.

Schroeder, C. E., Smiley, J., Fu, K. G., McGinnis, T., O'Connell, M. N., \& HaCKetT, T. A. (2003). Anatomical mechanisms and functional implications of multisensory convergence in early cortical processing. International Journal of Psychophysiology, 50, 5-17.

Sergent, J., Ohta, S., \& MacDonald, B. (1992). Functional neuroanatomy of face and object processing. A positron emission tomography study. Brain, 115, 15-36.

Stoeckel, M. C., Weder, B., Binkofski, F., Buccino, G., Shah, N. J., \& SEITZ, R. J. (2003). A fronto-parietal circuit for tactile object discrimination: An event-related fMRI study. NeuroImage, 19, 11031114.

Stoesz, M., Zhang, M., Weisser, V. D., Prather, S. C., Mao, H., \& Sathian, K. (2003). Neural networks active during tactile form perception: Common and differential activity during macrospatial and microspatial tasks. International Journal of Psychophysiology, 50, 41-49.

TAlairach, J., \& Tournoux, P. (1988). Co-planar stereotaxic atlas of the brain. New York: Thieme Medical.

Vandenberghe, R., Gitelman, D. R., Parrish, T. B., \& Mesulam, M. M. (2001). Functional specificity of superior parietal mediation of spatial shifting. NeuroImage, 14, 661-673.

Zangaladze, A., Epstein, C. M., Grafton, S. T., \& Sathian, K. (1999). Involvement of visual cortex in tactile discrimination of orientation. Nature, 401, 587-590.

(Manuscript received October 11, 2003; revision accepted for publication April 14, 2004.) 